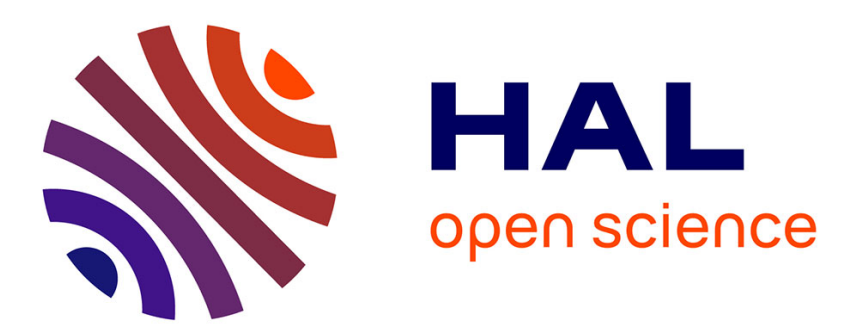

\title{
Induction Machine Fault Detection Enhancement Using a Stator Current High Resolution Spectrum
}

El Houssin El Bouchikhi, Vincent V. Choqueuse, Mohamed Benbouzid, Jean-Frederic Charpentier

\section{- To cite this version:}

El Houssin El Bouchikhi, Vincent V. Choqueuse, Mohamed Benbouzid, Jean-Frederic Charpentier. Induction Machine Fault Detection Enhancement Using a Stator Current High Resolution Spectrum. IECON 2012, Oct 2012, Montreal, Canada. pp.3913 - 3918, 10.1109/IECON.2012.6389267 . hal00773049

\author{
HAL Id: hal-00773049 \\ https://hal.science/hal-00773049
}

Submitted on 11 Jan 2013

HAL is a multi-disciplinary open access archive for the deposit and dissemination of scientific research documents, whether they are published or not. The documents may come from teaching and research institutions in France or abroad, or from public or private research centers.
L'archive ouverte pluridisciplinaire HAL, est destinée au dépôt et à la diffusion de documents scientifiques de niveau recherche, publiés ou non, émanant des établissements d'enseignement et de recherche français ou étrangers, des laboratoires publics ou privés. 


\title{
Induction Machine Fault Detection Enhancement Using a Stator Current High Resolution Spectrum
}

\author{
El Houssin El Bouchikhi, Vincent Choqueuse, Mohamed Benbouzid and Jean Frédéric Charpentier
}

\begin{abstract}
Fault detection in squirrel cage induction machines based on stator current spectrum has been widely investigated. Several high resolution spectral estimation techniques have been developed and used to detect induction machine abnormal operating conditions. In this paper, a modified version of MUSIC algorithm has been developed based on the faults characteristic frequencies. This method has been used to estimate the stator current spectrum. Then, an amplitude estimator has been proposed and a fault indicator has been derived for fault severity measurement. Simulated stator current data issued from a coupled electromagnetic circuits approach has been used to prove the appropriateness of the method for air gap eccentricity and broken rotor bars faults detection.
\end{abstract}

Index Terms-Induction machine, fault detection, signal processing, power spectral density estimation.

\section{INTRODUCTION}

In a wide variety of industrial applications, an increasing demand exists to improve reliability, availability, and safety of electrical systems. A sudden failure of a system may lead to cost expensive downtime, damage to surrounding equipment or even danger to humans. Induction machine is omnipresent in these electrical systems. Although it is robust and reliable, the induction machine is subjected to several faults. Common failures that may occur can be roughly classified into stator winding short circuit, broken rotor bar, broken end-ring, rotor eccentricity, bearing faults, shaft misalignment and load faults [1], [2]. In spite of the advances in failures detection, condition monitoring of induction machine is still a challenging task for engineers and researchers [3], [4] in order to emphasize the predictive maintenance.

A common approach for faults monitoring is vibration monitoring [5]-[7]. However, this method is expensive since it requires costly additional transducers. A cost-effective alternative is stator current supervision since current measurement requires limited number of sensors and it is already available for control and protection purposes. A literature survey showed the interest of the approach for mechanical and electrical faults detection [8]-[10]. Most authors perform the fault detection by monitoring the additional frequency components introduced by the fault but no precise stator current model is given. In various

E.H. El Bouchikhi, V. Choqueuse and M.E.H. Benbouzid are with the University of Brest, EA 4325 LBMS, Rue de Kergoat, CS 93837, 29238 Brest Cedex 03, France (e-mail: El-Houssin.Elbouchikhi@univ-brest.fr, Vincent.Choqueuse@univ-brest.fr, Mohamed.Benbouzid@univ-brest.fr).

J.F. Charpentier is with the French Naval Academy, IRENav EA 3634, 29240 Brest Cedex 9, France (e-mail: Jean-Frederic.Charpentier@ecolenavale.fr).

This work was supported by Brest Métropole Océane (BMO). works, numerical machine models accounting for the fault are used without providing analytical stator current expressions [11].

Theoretical analysis has shown that faulty machine frequencies of interest are given by [4]

$$
f_{k}=f_{s} \pm k f_{c}, k=0,1, \cdots, L .
$$

where $f_{s}$ is the the electrical supply frequency, $f_{c}$ corresponds to the fault characteristic frequency, and $2 \times L$ is the sidebands number. These frequencies are associated to air gap eccentricity, bearing failures or broken rotors bar faults.

In steady-state condition, $f_{s}$ and $f_{c}$ are constants and techniques based on classical spectral estimators (Periodogram and its extensions) have been employed [3], [12]. In order to overcome the poor resolution of these techniques, high resolution techniques have been proposed which require an a priori knowledge about the signal such as MUSIC and ESPRIT [13]-[16]. In non stationary environment, more sophisticated techniques have been investigated such as timefrequency representations [17], [18] and time-scale techniques [19]. However, despite the rich literature, none of them exploit the particular structure of the frequency content in (1).

In this paper, we propose a stator signal analytical model that takes into account the particular structure of the fault sensitive frequencies given by (1). A stator signal model is of great interest since it helps to develop suitable post-processing tools and detection strategies. Then, a high resolution power spectral density (PSD) estimate is developed based on this signal model for fault detection.

The fault detection technique proposed, herein, is based on three steps. First, the fundamental frequency, the fault characteristic frequency and the number of sidebands are estimated based on a modified version of MUSIC. Then, the maximum likelihood estimator, which is an optimal technique, is used to estimate the amplitude of the fault characteristic components. Finally, a fault detection criterion is computed from the estimated amplitudes.

To illustrate the difference between the classical MUSIC algorithm [20] and the proposed technique, Fig. 1 presents the MUSIC pseudo-spectrum and our modified version for a supply frequency of $f_{s}=50 \mathrm{~Hz}$, a fault characteristic frequency of $f_{c}=10 \mathrm{~Hz}$, and with $50 \mathrm{~dB}$ signal-to-noise ratio (SNR). Figure 1(a) shows that the MUSIC pseudo-spectrum exhibits spectral peaks at $f_{s} \pm k f_{c}$. In contrast to classical MUSIC, the proposed technique tracks the supply frequency and the characteristic frequency in a two-dimensional space. Figure 1(b) shows that the modified cost function exhibits a 


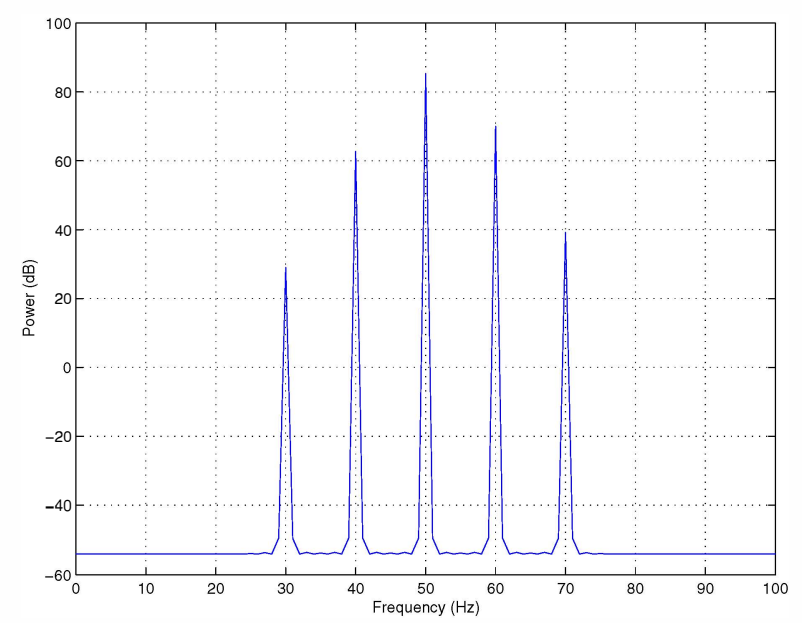

(a) Pseudospectrum estimate via MUSIC

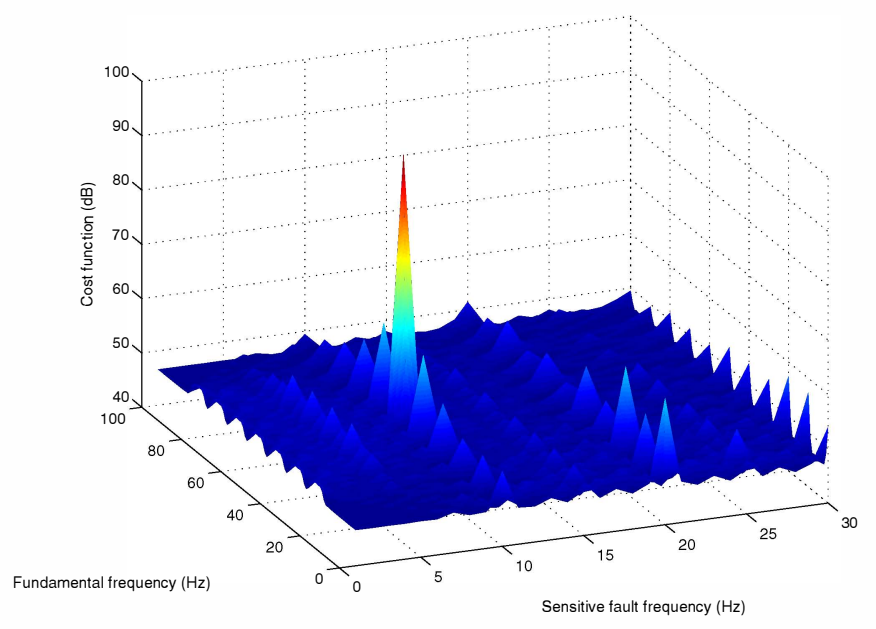

(b) Modified version of MUSIC

Fig. 1: Cost function for classical MUSIC and customized MUSIC (cost function in the case of a synthetic signal with $f_{s}=50 \mathrm{~Hz}, f_{c}=10 \mathrm{~Hz}, L=2$ and $S N R=50 \mathrm{~dB}$ ).

single peak at $f_{s}=50 \mathrm{~Hz}$ and $f_{c}=10 \mathrm{~Hz}$. As compared to MUSIC, the proposed technique makes the estimation of $f_{s}$ and $f_{c}$ (and the subsequent processing) easier. Furthermore, as it exploits more information about the signal, the proposed technique is expected to outperform the classical MUSIC algorithm.

The remaining parts of the present work are organized as follows. Section II analyses the effects of machine fault on the stator current and presents a stator current signal analytical model. Section III describes the fault detection method proposed in this paper. Simulation results are presented in section IV for broken rotor bars and air gap eccentricity detection in induction machine and section $\mathrm{V}$ concludes the work.

\section{Induction Machine Stator CuRRent Model}

In this section, we propose a stator current signal model for healthy and faulty machines.

\section{A. Fault Effect on Stator Current}

The following section presents the effects of broken rotor bar or air gap eccentricity on the stator current. A broken rotor bars and air gap eccentricity can be detected by monitoring the machine current spectral components produced by the magnetic field anomaly. This condition monitoring approach provides the advantage of not requiring any knowledge about the machine construction.

The broken rotor bar and air gap eccentricity sensitive frequencies are given by (2) and (3), respectively [4].

$$
\begin{aligned}
& f_{b r b}=f_{s}\left[k\left(\frac{1-s}{p}\right) \pm s\right] \\
& f_{e c c}=f_{s}\left[1 \pm m\left(\frac{1-s}{p}\right)\right]
\end{aligned}
$$

where

- $f_{s}$ is the electrical supply frequency;

$-p$ is the number of pole pairs;

$-s$ is the per-unit slip;

- $k / p=1,5,7,11, \ldots$;

- $m=1,2,3, \ldots$.

These faults characteristic frequencies can be expressed in the general form of (1) [21]. In the following, we propose a stator current signal model based on these characteristic frequencies.

\section{B. Signal Model}

In this paper, we consider a stator current signal model composed of $2 \times L+1$ complex-valued sinusoids. The signal is assumed to be corrupted by an additive white noise. Using (1), the stator current can be expressed as:

$$
x[n]=\sum_{k=-L}^{L} a_{k} e^{j\left(\left(\omega_{s}+k \omega_{c}\right) n+\phi_{k}\right)}+b[n]
$$

where

- The normalised pulsations $f_{s}$ and $f_{c}$ are defined as

$$
\begin{aligned}
& \omega_{s}=2 \pi f_{s} / F_{s} \\
& \omega_{c}=2 \pi f_{c} / F_{s}
\end{aligned}
$$

where $F_{s}$ corresponds to the sampling rate;

$-a_{k}$ and $\phi_{k}$ denote the amplitude and the phase of the $k^{\text {th }}$ sinusoid;

- $b[n] \sim \mathcal{N}_{c}\left(0, \sigma^{2}\right)$ is a complex circular white Gaussian noise i.e.:

$$
\begin{aligned}
E[b(n)] & =0 \\
E[b(n) b(n+\tau)] & =0 \\
E\left[b(n) b^{*}(n+\tau)\right] & =\sigma^{2} \delta(\tau)
\end{aligned}
$$

where $E\{\},.(.)^{*}$ and $\delta($.$) corresponds to the statistical$ expectation, the complex conjugate and the Dirac delta, respectively. 
One can notice that if $f_{s}=0 \mathrm{~Hz}$ then the signal corresponds to a periodic waveform. Furthermore, if $f_{c}=0 \mathrm{~Hz}$ or $L=0$ then the model reduces to a single complex sine wave embedded in Gaussian noise.

Let us construct the $M \times 1$ column vector, $\mathbf{x}[n]$, which contains $M$ consecutive samples of the observed signal i.e.

$$
\mathbf{x}[n]=[x[n], \cdots, x[n+M-1]]^{T}
$$

where $(.)^{T}$ denotes the matrix transpose. Using a matrix notation, (4) can be expressed as

$$
\mathbf{x}[n]=\mathbf{D}\left(f_{s}\right) \mathbf{A}\left(f_{c}\right) \mathbf{s}[n]+\mathbf{b}[n]
$$

where:

- $\mathbf{b}[n]$ is a $M \times 1$ column vector containing the noise samples. This vector is defined as:

$$
\mathbf{b}[n]=[b[n], \cdots, b[n+M-1]]^{T}
$$

- $\mathbf{s}[n]$ is a $(2 \times L+1) \times 1$ column vector containing the complex sine waves parameters. This vector is defined as:

$\mathbf{s}[n]=\left[a_{-L} e^{j\left(\left(\omega_{s}-L \omega_{c}\right) n+\phi_{-L}\right)}, \cdots, a_{L} e^{j\left(\left(\omega_{s}+L \omega_{c}\right) n+\phi_{L}\right.}\right]^{T}$

- $\mathbf{D}\left(f_{s}\right)$ is a $M \times M$ diagonal matrix whose elements are given by

$$
\mathbf{D}\left(f_{s}\right)=\left[\begin{array}{cccc}
1 & 0 & \cdots & 0 \\
0 & e^{j \omega_{s}} & \ddots & \vdots \\
\vdots & \ddots & \ddots & 0 \\
0 & \cdots & 0 & e^{j \omega_{s}(M-1)}
\end{array}\right]
$$

- $\mathbf{A}\left(f_{c}\right)$ is a $M \times(2 L+1)$ matrix whose elements are given by

$$
\mathbf{A}\left(f_{c}\right)=\left[\begin{array}{ccc}
1 & \cdots & 1 \\
e^{-j L \omega_{c}} & \cdots & e^{j L \omega_{c}} \\
\vdots & \vdots & \vdots \\
e^{-j L \omega_{c}(M-1)} & \cdots & e^{j L \omega_{c}(M-1)}
\end{array}\right]
$$

Using the signal model in (11), we propose to estimate the model parameters from $x(n)(n=0, \cdots, N-1)$, where $N$ corresponds to the signal length. The proposed technique relies on the following assumption:

- $\mathcal{H}_{1}$ : The matrix $\mathbf{D}\left(f_{s}\right) \mathbf{A}\left(f_{c}\right)$ has rank $2 L+1$ which implies that $M>2 L+1$ and $f_{c} \neq 0 \mathrm{~Hz}$.

\section{High Resolution Fault Signature AnAlysis}

In this section, we describe our power spectrum density estimator based on a customized version of MUSIC. Then, we derive the maximum likelihood estimator of the amplitudes,. Finally, we describe the proposed criterion for fault detection.

\section{A. Frequency Estimation}

Assuming that the phases of the complex sinusoids are independent and uniformly distributed on the interval $[-\pi, \pi[$, the covariance matrix is given by

$$
\begin{aligned}
\mathbf{R}= & E\left\{\mathbf{x}[n] \mathbf{x}^{H}[n]\right\} \\
= & E\left\{\left(\mathbf{D}\left(f_{s}\right) \mathbf{A}\left(f_{c}\right) \mathbf{s}[n]+\mathbf{b}[n]\right)\right. \\
& \left.\times\left(\mathbf{D}\left(f_{s}\right) \mathbf{A}\left(f_{c}\right) \mathbf{s}[n]+\mathbf{b}[n]\right)^{H}\right\} \\
= & \left(\mathbf{D}\left(f_{s}\right) \mathbf{A}\left(f_{c}\right)\right) \mathbf{P}\left(\mathbf{D}\left(f_{s}\right) \mathbf{A}\left(f_{c}\right)\right)^{H}+\sigma^{2} \mathbf{I}_{M}
\end{aligned}
$$

where $\mathrm{E}\{$.$\} denotes the statistical expectation, (. )^{H}$ refers to Hermitian matrix transpose, $\mathbf{I}_{M}$ is the $M \times M$ identity matrix and

$$
\mathbf{P}=E\left\{\mathbf{s}[n] \mathbf{s}^{H}[n]\right\} .
$$

The covariance matrix eigenvalues decomposition can be written as follows

$$
\mathbf{R}=\mathbf{U} \Lambda \mathbf{U}^{H}
$$

where $\Lambda$ is a diagonal matrix containing the eigenvalues $\lambda_{1} \geq \cdots \geq \lambda_{M}$ of $\mathbf{R}$ and $\mathbf{U}$ is a unitary matrix containing the associated eigenvectors. Under the assumption $\mathcal{H}_{1}$ and the fact that $\mathbf{P}$ is non-singular, the diagonal matrix $\Lambda$ can be decomposed as

$$
\Lambda=\left[\begin{array}{cc}
\boldsymbol{\lambda} & \mathbf{0} \\
\mathbf{0} & \sigma^{2} \mathbf{I}_{M-2 L-1}
\end{array}\right]
$$

where $\lambda$ is a diagonal matrix containing the $2 \times L+1$ greatest eigenvalues of $\Lambda$. Figure 2 shows an ordered eigenvalues distribution model for a simulated signal composed of $2 L+1$ complex sine waves embedded in a white noise. Let us decompose $\mathbf{U}$ as

$$
\mathbf{U}=\left[\mathbf{U}_{s} \mathbf{G}\right]
$$

where:

- $\mathbf{U}_{s}$ is a $M \times(2 L+1)$ matrix formed from the eigenvectors associated with the $2 \times L+1$ greatest eigenvalues,

- $\mathbf{G}$ is a $M \times(M-2 L-1)$ matrix formed from the eigenvectors associated with the $M-(2 \times L+1)$ least significant ones.

Using (18), it can be shown that:

$$
\mathbf{R G}=\left(\mathbf{D}\left(f_{s}\right) \mathbf{A}\left(f_{c}\right)\right) \mathbf{P}\left(\mathbf{D}\left(f_{s}\right) \mathbf{A}\left(f_{c}\right)\right)^{H} \mathbf{G}+\sigma^{2} \mathbf{G}
$$

As $\mathbf{U}$ is a unitary matrix $\left(\mathbf{U}^{H} \mathbf{U}=\mathbf{I}_{M}\right), \mathbf{U}^{H} \mathbf{G}=\mathbf{0}$.Then, using (20) and (21) leads to

$$
\begin{aligned}
\mathbf{R G} & =\mathbf{U} \Lambda \mathbf{U}^{H} \mathbf{G} \\
& =\sigma^{2} \mathbf{G} .
\end{aligned}
$$

Substituting (25) in (23), we obtain the following result

$$
\left(\mathbf{D}\left(f_{s}\right) \mathbf{A}\left(f_{c}\right)\right) \mathbf{P}\left(\mathbf{D}\left(f_{s}\right) \mathbf{A}\left(f_{c}\right)\right)^{H} \mathbf{G}=\mathbf{0}
$$

which readily implies

$$
\left(\mathbf{D}\left(f_{s}\right) \mathbf{A}\left(f_{c}\right)\right)^{H} \mathbf{G}=\mathbf{0}
$$




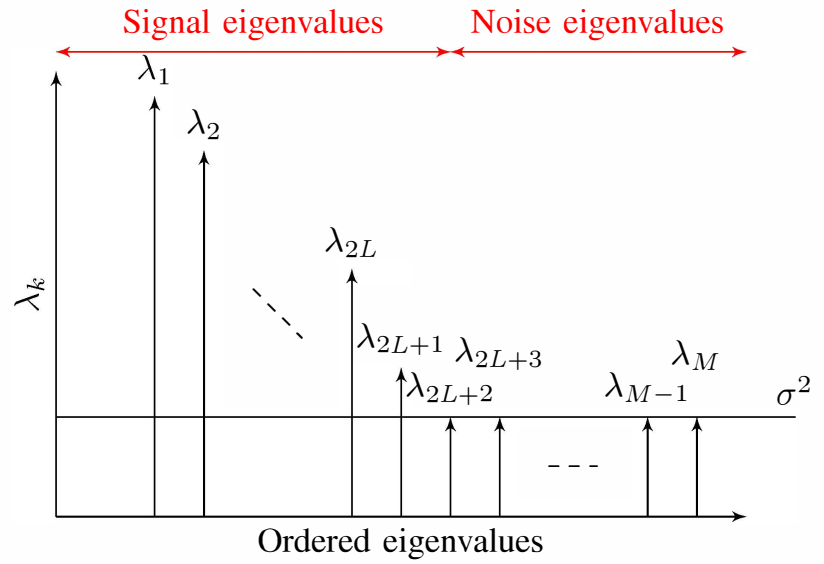

Fig. 2: Covariance matrix eigenvalues decomposition [20].

In practice, $\mathbf{R}$ is unknown, but it can be estimated from the available data. Let

$$
\widehat{\mathbf{R}}=\frac{1}{N-M+1} \sum_{n=0}^{N-M} \mathbf{x}[n] \mathbf{x}[n]^{H}
$$

be the estimator of the covariance matrix and $\widehat{\mathbf{U}}=\left[\widehat{\mathbf{U}}_{s} \widehat{\mathbf{G}}\right]$ be its corresponding eigenvectors, the frequencies $f_{s}$ and $f_{c}$ can be found as follows

$$
\left\{\widehat{f}_{s}, \widehat{f}_{c}\right\}=\arg \max _{\left\{f_{\bullet}, f_{1}\right\}} \mathcal{J}\left(f_{0}, f_{1}\right)
$$

where

$$
\mathcal{J}\left(f_{0}, f_{1}\right)=\frac{1}{\left\|\left(\mathbf{D}\left(f_{0}\right) \mathbf{A}\left(f_{1}\right)\right)^{H} \widehat{\mathbf{G}}\right\|_{F}^{2}}
$$

and where $\|\cdot\|_{F}^{2}$ denotes the Frobenius norm. If $\widehat{\mathbf{G}}=\mathbf{G}$, (27) and (30) show that the cost function $\mathcal{J}\left(f_{0}, f_{1}\right)$ tends to infinity for $f_{0}=f_{s}$ and $f_{1}=f_{c}$. In practice, as $\widehat{\mathbf{G}} \approx \mathbf{G}$, $\mathcal{J}\left(f_{s}, f_{c}\right)$ has a finite value. Figure 1(b) displays the cost function for a synthetic signal with $f_{s}=50 \mathrm{~Hz}, f_{c}=10 \mathrm{~Hz}$, $L=2$ and $S N R=50 \mathrm{~dB}$. One can note that the cost function exhibits a well-defined peak at $f_{0}=50 \mathrm{~Hz}$ and $f_{1}=10 \mathrm{~Hz}$.

The proposed approach requires a priori knowledge about the number of sidebands $L$ for the evaluation of the cost function. If the number of sidebands is unknown, the cost function can be modified to take into account the estimation of $L$. Indeed, by following the same approach as in [22], it can be shown that the fundamental frequency, the fault characteristic frequency, and the number of sidebands $L$ can be estimated by maximizing the following three-dimensional cost function

$$
\mathcal{J}_{c}\left(f_{s}, f_{c}, L\right)=\frac{(2 L+1) M(M-2 L-1)}{\left\|\left(\mathbf{D}\left(f_{s}\right) \mathbf{A}\left(f_{c}\right)\right)^{H} \widehat{\mathbf{G}}\right\|_{F}^{2}} .
$$

For a grid connected induction machine, the supply frequency $f_{s}$ is assumed to be known. Thus, exploiting this assumption, the cost function reduces to a two-dimensional one and the optimization problem can be solved using a twodimensional grid search. Figure 3 displays the proposed cost

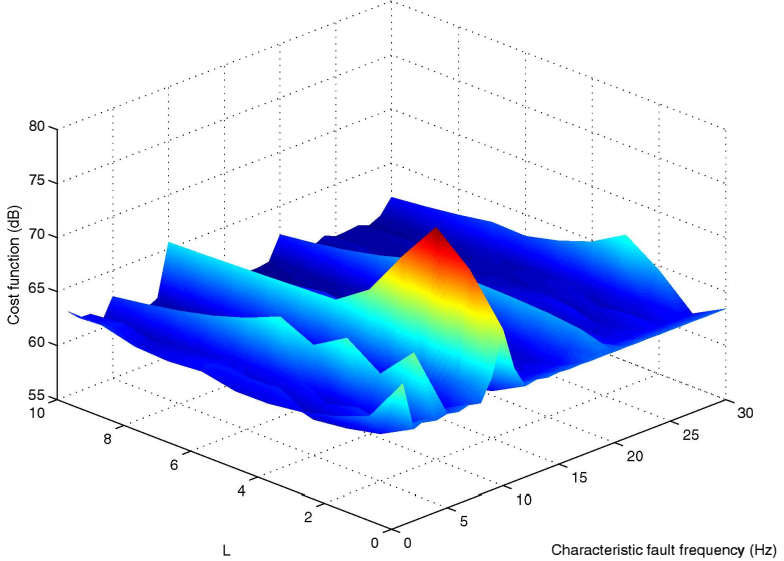

Fig. 3: Modified MUSIC cost function for the estimation of $L$ and $f_{c}$.

function for estimating the number of sidebands $L$, assuming that the fundamental frequency $f_{s}$ is known. The synthetic signal is the same as the one of Fig. $1\left(L=2, f_{c}=10 \mathrm{~Hz}\right)$. The figure shows that the proposed method correctly estimates $L$ and $f_{c}$. For fault detection, the estimation of $L$ is of great interest since it carries out the information about the fault existence. For $L=0$, the induction machine operate under healthy condition. When $L \neq 0$, a fault occurs and a criterion must be computed in order to determine the fault severity.

\section{B. Amplitude Estimation}

The amplitudes of the frequency components convey the information about the fault severity. These amplitudes are contained in the vector $\mathbf{s}[0]$, which is equal to

$$
\mathbf{s}[0]=\left[a_{-L} e^{j \phi_{-L}}, \cdots, a_{L} e^{j \phi_{L}}\right]^{T}
$$

Using the model given in (11) and fixing $M=N$, it can be shown that the maximum likelihood estimator (MLE) of $\mathbf{s}[0]$, denoted $\widehat{\mathbf{s}}[0]$, is given by [23]

$$
\widehat{\mathbf{s}}[0]=\left(\mathbf{D}\left(f_{s}\right) \mathbf{A}\left(f_{c}\right)\right)^{\dagger} \mathbf{x}[0]
$$

where $\left(\mathbf{D}\left(f_{s}\right) \mathbf{A}\left(f_{c}\right)\right)^{\dagger}$ is defined as

$$
\begin{aligned}
\left(\mathbf{D}\left(f_{s}\right) \mathbf{A}\left(f_{c}\right)\right)^{\dagger} & =\left(\mathbf{A}^{H}\left(f_{c}\right) \mathbf{D}^{H}\left(f_{s}\right) \mathbf{D}\left(f_{s}\right) \mathbf{A}\left(f_{c}\right)\right)^{-1} \\
& \times \mathbf{A}^{H}\left(f_{c}\right) \mathbf{D}^{H}\left(f_{s}\right)
\end{aligned}
$$

and where (.) $)^{-1}$ denotes the matrix inverse. Using (14), it can be shown that $\mathbf{D}\left(f_{s}\right)^{H} \mathbf{D}\left(f_{s}\right)=\mathbf{I}_{M}$. It follows that

$$
\widehat{\mathbf{s}}[0]=\left(\mathbf{A}^{H}\left(f_{c}\right) \mathbf{A}\left(f_{c}\right)\right)^{-1} \mathbf{A}^{\dagger}\left(f_{c}\right) \mathbf{D}^{H}\left(f_{s}\right) \mathbf{x}[0] .
$$

Let us decompose the $(2 L+1) \times 1$ column vector $\widehat{\mathbf{s}}[0]$ as

$$
\widehat{\mathbf{s}}[0]=\left[\widehat{s}_{-L}, \widehat{s}_{-L+1}, \cdots, \widehat{s}_{L-1}, \widehat{s}_{L}\right]^{T} .
$$

Using the structure of $\mathbf{s}[0]$ in (32), the amplitude $a_{k}$ can be estimated by

$$
\widehat{a}_{k}=\left|\widehat{s}_{k}\right| \text {. }
$$


The MLE of the amplitude of the complex sinusoids is efficient [23, Theorem 7.5]. Note that in practice $f_{c}$ and $f_{s}$ are unknown and must be replaced by their estimates in (35) (see the previous subsection for details).

\section{Fault Detection Criterion}

In order to successfully perform fault detection, a fault criterion is required to measure the machine state and fault severity. Since the information about the fault is carried out by the sidebands amplitude $a_{k}(k \neq 0)$, we propose to compute the sidebands energy to fundamental frequency energy ratio as a fault indicator. This criterion is expressed mathematically as

$$
\mathcal{C}=\sum_{k=-L, k \neq 0}^{L}\left(\frac{\widehat{a}_{k}^{2}}{\widehat{a}_{0}^{2}}\right)
$$

This criterion allows to measure the fault severity. It can be used as an input for fault decision algorithm allowing to automatically take decision on the operating state and condition of the machine and detecting any abnormal operating conditions.

The fault detection algorithm is summed up in Fig. 4.

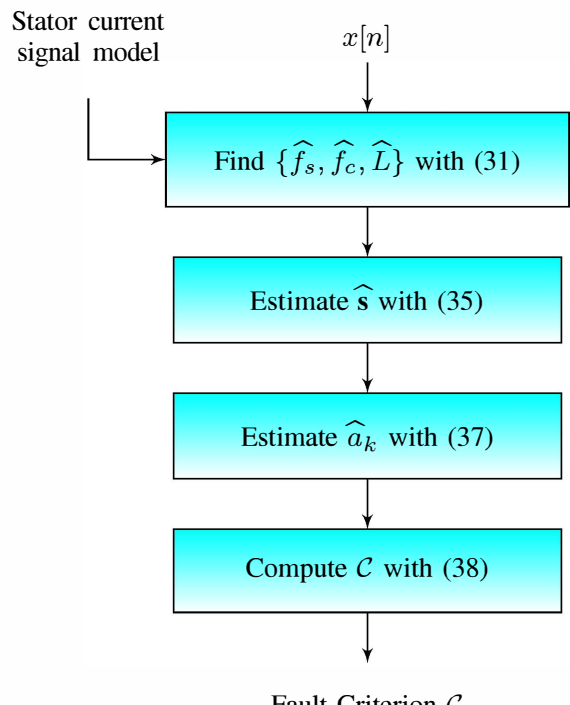

Fig. 4: Flowchart of the fault detection algorithm.

\section{Application to Induction Machine Faults DETECTION}

This section presents the simulation results. The approach proposed has been used to detect broken rotor bars and air gap eccentricity whose characteristic frequencies match the analytical stator current model presented in (1). The simulated stator currents are issued from a $4 \mathrm{~kW}$ induction machine model, based on the coupled electromagnetic circuits approach [11]. The two faults have been implemented and stator currents have been retrieved at $10 \mathrm{kHz}$ sampling rate for $2 \mathrm{~s}$. Then, one phase stator current has been processed for fault detection and the
TABLE I: Modified MUSIC: results for simulated healthy and faulty machines for $L=2$.

\begin{tabular}{|c|c|c|c|c|}
\hline State & $\begin{array}{c}f_{c} \\
(\mathrm{~Hz})\end{array}$ & $\begin{array}{c}f_{s} \\
(\mathrm{~Hz})\end{array}$ & $\widehat{a}_{k}$ & $\begin{array}{c}\mathcal{C} \\
\left(\times 10^{-4}\right)\end{array}$ \\
\hline Healthy & 23.24 & 50 & $\begin{array}{c}a_{-2}=0.0069 \\
a_{-1}=0.019 \\
a_{0}=3.33 \\
a_{1}=0.0076 \\
a_{2}=0.0075\end{array}$ & 0.49 \\
\hline $\begin{array}{c}\text { Static } \\
\text { eccentricity }\end{array}$ & 24.44 & 50 & $\begin{array}{c}a_{-2}=0.0003 \\
a_{-1}=0.084 \\
a_{0}=3.27 \\
a_{1}=0.036 \\
a_{2}=0.0107\end{array}$ & 7.85 \\
\hline $\begin{array}{l}\text { Dynamic } \\
\text { eccentricity }\end{array}$ & 24.44 & 50 & $\begin{array}{c}a_{-2}=0.0021 \\
a_{-1}=0.26 \\
a_{0}=3.31 \\
a_{1}=0.0114 \\
a_{2}=0.0066\end{array}$ & 63 \\
\hline $\begin{array}{c}\text { Mixed } \\
\text { eccentricity }\end{array}$ & 24.44 & 50 & $\begin{array}{c}a_{-2}=0.0 .039 \\
a_{-1}=0.27 \\
a_{0}=3.29 \\
a_{1}=0.074 \\
a_{2}=0.0 .13\end{array}$ & 90 \\
\hline
\end{tabular}

TABLE II: Modified MUSIC: results for simulated healthy and faulty machines with $L$ estimation for air gap eccentricity.

\begin{tabular}{|c||c|c|c|}
\hline State & $\begin{array}{c}\widehat{f}_{c} \\
(\mathrm{~Hz})\end{array}$ & $\widehat{L}$ & $\begin{array}{c}\mathcal{C} \\
\left(\times 10^{-4}\right)\end{array}$ \\
\hline Healthy & -- & 0 & 0 \\
\hline Static eccentricity & 24.96 & 3 & 6.17 \\
\hline Dynamic eccentricity & 24.66 & 3 & 21 \\
\hline Mixed eccentricity & 24.54 & 3 & 72 \\
\hline
\end{tabular}

fault criterion $\mathcal{C}$ has been computed in order to measure the fault severity.

\section{A. Air Gap Eccentricity Detection}

Approximately $80 \%$ of the mechanical faults lead to nonuniformity between rotor and stator [1], [2]. This uniformity leads to air gap eccentricity, which includes static, dynamic and mixed eccentricities. In the following, we present the performance of the proposed approach for eccentricity detection. Table I gives the simulation results for healthy and faulty machines using the modified MUSIC by assuming that $L$ is known and equals 2 .

These results demonstrate the appropriateness of the approach proposed. However underestimating or overestimating $L$ may lead to false results and then to wrong conclusions on the machine operating state. Then, the modified MUSIC for $L$ estimation has been used to enhance the detection procedure.

The simulation results given in table II show that the estimation of $L$ improves the frequency estimation and gives best performances. The same approach has been used for broken rotor bars detection. 
TABLE III: Modified MUSIC: results for simulated healthy and faulty machines with $L$ estimation for broken rotor bars.

\begin{tabular}{|c||c|c|c||c|}
\hline State & $\begin{array}{c}\widehat{f}_{s} \\
(\mathrm{~Hz})\end{array}$ & $\begin{array}{c}\widehat{f}_{c} \\
(\mathrm{~Hz})\end{array}$ & $\widehat{L}$ & $\begin{array}{c}\mathcal{C} \\
\left(\times 10^{-4}\right)\end{array}$ \\
\hline Healthy & 50 & -- & 0 & 0 \\
\hline 1 broken bar & 50.12 & 88.25 & 1 & 27.87 \\
\hline 2 broken bars & 50.12 & 87.6 & 1 & 118 \\
\hline 3 broken bars & 50.12 & 86.72 & 1 & 192.9 \\
\hline
\end{tabular}

\section{B. Broken Rotor Bars Detection}

Broken rotor bar is one of the electrical faults that is difficult to detect since the squirrel cage current can not be acquired. Computer simulations have been performed for assessment of operating features of the proposed fault detection scheme. In order to reduce the size of the signal, while preserving the relevant information, and to decrease the computational complexity, the original signal has been down-sampled. Table III gives the simulation results for 1 to 3 broken rotor bars. The broken bars are adjacent. The criterion has been evaluated for different fault degrees. It can be noticed that the fault criterion varies in proportion to the number of broken rotor bars. It should be stressed that the estimation of $L$ is of great interest since it allows to improve the frequency estimation (determine the borders between the signal subspace and noise subspace which is the most important step on MUSIC algorithm). Furthermore, It permits to enhance the sensitivity of the fault criterion.

\section{CONClusion}

This paper dealt with the induction machine broken rotor bars and air gap irregularities detection. It has been proposed a new fault detection scheme using the stator current. A modified MUSIC with model order estimation has been developed and used for fault detection. This method can be adapted to any kind of faults assuming that the fault characteristic model is known.

The technique effectiveness has been confirmed using simulation data issued from a coupled electromagnetic circuits approach. It is expected to experimentally validate the simulation results. Further investigations will be performed in order to validate the proposed approach for variable frequency power supply and adjustable speed drives.

\section{REFERENCES}

[1] P. Zhang, Y. Du, T. Habetler, and B. Lu, "A survey of condition monitoring and protection methods for medium-voltage induction motors," IEEE Trans. on Industry Applications, vol. 47, no. 1, pp. 34-46, Jan./Feb. 2011.

[2] A. H. Bonnett and C. Yung, "Increased efficiency versus increased reliability," IEEE Industry Applications Magazine, vol. 14, no. 1, 2008.

[3] A. Bellini, F. Filippetti, C. Tassoni, and G. A. Capolino, "Advances in Diagnostic Techniques for Induction Machines," IEEE Trans. on Industrial Electronics, vol. 55, no. 12, pp. 4109-4126, Dec. 2008.

[4] M. E. H. Benbouzid, "A review of induction motors signature analysis as a medium for faults detection," IEEE Transactions on Industrial Electronics, vol. 47, no. 5, pp. 984-993, Oct. 2000.
[5] L. Guo, J. Chen, and X. Li, "Rolling bearing fault classification based on enveloppe spectrum and support vector machine," Journal of Vibration and Control, vol. 15, no. 9, pp. 1349-1363, Jul. 2009.

[6] H. Ocak and K. Loparo, "A new bearing fault detection and diagnosis schema based on hidden markov modeling of vibration signals," in Proceedings of the 2001 ICASSP, Salt Lake City (USA), 2001, pp. 31413144.

[7] D. G. Dorrell, W. T. Thomson, and S. Roach, "Analysis of airgap flux, current, and vibration signals as a function of the combination of static and dynamic airgap eccentricity in 3-phase induction motors," IEEE Transactions on Industry Applications, vol. 33, no. 1, pp. 24-34, Jan./Fer. 1997.

[8] V. Choqueuse, M. E. H. Benbouzid, Y. Amirat, and S. Turri, "Diagnosis of three-phase electrical machines using multidimensional demodulation techniques," IEEE Transactions on Industrial Electronics, vol. 59, no. 4, pp. 2014-2023, April 2012.

[9] M. Blodt, J. Regnier, and J. Faucher, "Distinguishing load torque oscillations and eccentricity faults in induction motors using stator current wigner distributions," IEEE Transactions on Industry Applications, vol. 45, no. 6, pp. 1991-2000, Nov./Dec. 2009.

[10] S. Kia, H. Henao, and G. Capolino, "Analytical and experimental study of gearbox mechanical effect on the induction machine stator current signature," IEEE Trans. on Industry Applications, vol. 45, no. 4, pp. 1405-1415, Jul./Aug. 2009.

[11] A. Ceban, R. Pusca, and R. Romary, "Study of rotor faults in induction motors using external magnetic field analysis," IEEE Transactions on Industrial Electronics, vol. 59, no. 5, pp. 2082-2096, May 2012.

[12] M. E. H. Benbouzid and G. B. Kliman, "What stator current processing based technique to use for induction motor rotor faults diagnosis?" IEEE Transactions on Energy Conversion, vol. 18, no. 2, pp. 238-244, June 2003.

[13] M. E. H. Benbouzid, M. Vieira, and C. Theys, "Induction motors faults detection and localization using stator current advanced signal processing techniques," IEEE Transactions on Power Electronics, vol. 14, no. 1 Jan. 1999.

[14] A. Garcia-Perez, R. de Jesus Romero-Troncoso, E. Cabal-Yepez, and R. Osornio-Rios, "The application of high-resolution spectral analysis for identifying multiple combined faults in induction motors," IEEE Transactions on Industrial Electronics, vol. 58, no. 5, pp. 2002-2010, May 2011.

[15] A. Bracale, G. Carpinelli, L. Piegari, and P. Tricoli, "A high resolution method for on line diagnosis of induction motors faults," in Proceedings of the 2007 IEEE PowerTech, Lausanne (Suisse), 2007, pp. 994-998.

[16] S. H. Kia, H. Henao, and G. Capolino, "A high-resolution frequency estimation method for three-phase induction machine fault detection," IEEE Trans. on Industrial Electronics, vol. 54, no. 4, Aug. 2007.

[17] E. H. El Bouchikhi, V. Choqueuse, M. E. H. Benbouzid, J. Charpentier, and G. Barakat, "A comparative study of time-frequency representations for fault detection in wind turbine," in Proceedings of the 2011 IECON, Melbourne (Australia), Nov. 2011, pp. 3584-3589.

[18] M. Blodt, M. Chabert, J. Regnier, and J. Faucher, "Mechanical load fault detection in induction motors by stator current time-frequency analysis," IEEE Trans. on Industry Applications, vol. 42, no. 6, pp. 1454-1463, Nov./Dec. 2006.

[19] J.Pons-Llinares, J. Antonino-Daviu, M. Riera-Guasp, M. PinedaSanchez, and V. Climente-Alarcon, "Induction motor diagnosis based on a transient current analytic wavelet transform via frequency b-splines," IEEE Trans. Industrial Electronics, vol. 58, no. 5, pp. 1530-1544, May 2011.

[20] P. Stoica and R. Moses, Introduction to Spectral Analysis. Prentice Hall, 1997.

[21] R. Schoen, B. Lin, T. Habetler, J. Schlag, and S. Farag, "An unsupervised, on-line system for induction motor fault detection using stator current monitoring," Industry Applications, IEEE Transactions on, vol. 31, no. 6, pp. $1280-1286$, Nov./Dec. 1995.

[22] M. G. Christensen, A. Jakobsson, and S. H. Jensen, "Joint highresolution fundamental frequency and order estimation," IEEE Trans. Audio, Speech, and Language Processing, vol. 15, no. 5, pp. 1635-1644, July 2007.

[23] S. Kay, Fundamentals of Statistical Signal Processing: Estimation Theory. Prentice-Hall signal processing series, 1993, 17th Printing. 